\title{
The influence of gendered roles and responsibilities on the adoption of technologies that mitigate drought risk: The case of drought-tolerant maize seed in eastern Uganda
}

\author{
Authors: Monica Fisher 1, 3, 4 and Edward R. Carr ${ }^{2}$ \\ ${ }^{1}$ International Maize and Wheat Improvement Center, CIMMYT-Ethiopia, PO Box 5689, Addis \\ Ababa, Ethiopia. \\ ${ }^{2}$ Humanitarian Response and Development Lab, Department of Geography, University of South \\ Carolina, Columbia, South Carolina, USA. Email: edwardrcarr@gmail.com. \\ ${ }^{3}$ Present address: Applied Economics Department, 213 Ballard Extension Hall, Oregon State \\ University, Corvallis, Oregon, 97331, USA. Email: monica.fisher@oregonstate.edu. Telephone: \\ +1-541-602-2280. Fax: +1-541-737-2563. \\ ${ }^{4}$ Corresponding Author
}

\section{Acknowledgements}

This work was done under the Drought Tolerant Maize for Africa (DTMA) project, funded by the Bill \& Melinda Gates Foundation. The authors wish to thank Endeshaw Habte Hailemichael, Woinishet Asnake, William Ekere, Mywish Maredia, Godfrey Asea, and the outstanding team or field supervisors and enumerators for collaboration on the design and implementation of the Uganda survey. Many thanks are due to our respondents at the study sites. 


\section{Introduction}

Maize is a central component of food security and economic wellbeing for more than 32 million households in sub-Saharan Africa (SSA) (personal communication, Tsedeke Abate, March 2015). In SSA, maize cultivation is almost completely rain-fed, and therefore dependent on the region's variable precipitation. Around 40\% of Africa's maize-growing area faces occasional drought stress in which yield losses are $10-25 \%$. Around $25 \%$ of the maize crop suffers frequent drought, with losses of up to half the harvest (CIMMYT, 2013). Some climate change models have consistently predicted increased incidence of drought for SSA (Li et al. 2009), so drought-related challenges to achieving food security will likely continue and possibly increase.

African farmers are not helpless in the face of variable and changing climates; they already adapt to climate variability and change in a multiplicity of ways (Deressa et al., 2009; Carr, 2008a; Kinsey et al., 1998; Fisher et al., 2010). However, in some parts of SSA, the magnitude and speed of the predicted changes are likely to outstrip the local efforts to manage those changes, and large public and private investments in crop breeding, irrigation infrastructure, and safety nets (e.g., micro-insurance) are needed to meet the food needs of the growing human population (Burke and Lobell, 2010).

While the development of new seed technologies that can manage the stresses of likely future climatic variability and change presents numerous technical challenges, ensuring these seeds meet the needs of a diverse set of farmers presents another crucial, yet less-considered, challenge. This challenge is particularly clear when considering the needs and preferences of 
men and women farmers. While modern seed varieties are intended to benefit a wide range of producers, empirical studies reveal that women farmers have relatively low rates of adoption of agricultural technologies associated with increased crop yields (Peterman et al., 2010). Further, research suggests that men are more likely than women to adopt measures for adapting to climate change, such as soil conservation, tree planting, and changing crop varieties (Deressa et al., 2009). Where gender gaps characterize the adoption of agricultural technologies, women’s empowerment is challenged and societies experience real costs in terms of untapped potential in agricultural output, food security, and economic growth (Ragassa, 2012).

This paper addresses the character and causes of apparent gender gaps in the adoption of modern seed varieties through the case of the Drought Tolerant Maize for Africa (DTMA) project. To reduce the sensitivity of farming systems to drought and improve food security, DTMA has developed about 190 drought-tolerant (DT) maize varieties between 2007 and 2014. Through national agricultural research systems and private seed companies, these varieties have been extended and released to farmers in 13 SSA countries (CIMMYT, 2013). On-farm trials across a range of sites in East and Southern Africa revealed that DT maize varieties out-yield popular commercial checks by 83-137\% (controlled drought), 26-47\% (random drought), and 25-56\% (optimal rainfall conditions) (personal communication, Tsedeke Abate, March 2015). At the same time, it is clear that women farmers are slow to adopt the new DT maize varieties (see Figure 1). ${ }^{1}$ The figure reveals a narrower gender gap in adoption in the case of non-DT modern

\footnotetext{
${ }^{1}$ Modern maize is here defined as hybrid, recycled hybrid, or open pollinated varieties (OPVs), and is contrasted with local maize varieties. While modern maize varieties are the result of crop science breeding, local varieties are the product of centuries of selection by farmers and the natural environment. We also contrast drought tolerant (DT) and non-DT modern maize, in that DT modern maize was bred to be tolerant to drought, whereas non-DT modern maize was bred for traits other than drought tolerance (e.g., yield, early maturity, disease resistance).
} 
maize (i.e. modern maize bred for traits other than drought tolerance) vs. DT modern maize. Because non-DT varieties have been in circulation for longer than DT varieties, this trend may suggest prospects for reducing the gap in DT maize cultivation rates among women and men farmers over time. Nonetheless, the fact remains that in Uganda the initial uptake of DT modern maize is marked by a significant gender gap.

\section{[Insert Figure 1]}

In this paper, we seek to understand how gendered roles and responsibilities influence adoption of DT maize in SSA, and therefore uncover opportunities to address and lessen genderbased differences in seed adoption. Addressing this challenge could broaden access to the potential benefits for climate change adaptation that may proceed from seed use. The paper begins with a brief overview of the place of gender in African agriculture and agricultural decision-making to frame the issue of how gender-based roles and responsibilities impact seed adoption. Household survey data for Uganda are used to empirically study local patterns of landholding and agricultural decision-making. Regression models are estimated in order to test hypotheses for the observed gender gap in DT maize adoption and to gain insights into the impact of gendered roles and responsibilities on adoption of new agricultural technologies. Empirical model results are assessed in terms of whether or not they support or refute the study hypotheses and their implications for the development of well-targeted and socially-inclusive adaptation policies (Below et al., 2012).

\section{Gender and agricultural decision-making in sub-Saharan Africa}

While it appears that DT maize presents significant benefits to African farmers, the uptake of any new agricultural technology is governed by more than its utility. A farmer's 
characteristics, such as gender, age, and income, shape his or her roles and responsibilities with regard to agricultural production and livelihoods (e.g. Carr, 2008b; Simtowe, 2010; Buechler, 2009; Koopman, 2009; Molua, 2010), and therefore strongly influence the decision to adopt a new technology. Women are heavily engaged in agricultural production across SSA. However, in many contexts agricultural decision-making falls outside their roles and responsibilities, and women are, therefore, unable to adopt new farm technologies. For example, among the Bambara in Mali, agricultural decision-making is largely concentrated in the hands of senior men in an extended family (Becker. 1990; Akeredolu et al., 2007; Grigsby, 2004), limiting women’s use of new agricultural and adaptation technologies like climate services (Carr, 2014). In other cases, women may not make decisions on agricultural technology uptake, but may still influence those decisions. Negotiation between a husband and wife over the demand for her labor, for example, can have profound effects on the rate of adoption of labor-increasing technologies. For example, studies in Mali and Cameroon have found that agricultural technology adoption occurred but husbands had to compensate their wives for increased labor supply (e.g., Lilja, 1996; Jones, 1986). Other research has found that, in a range of settings, wives simply refused to supply labor, opting instead to devote time to their own enterprises (for a review, see Blumberg, 1991).

Among farmers who have agricultural decision-making responsibilities, the expectations associated with different social categories can constrain their decisions. Much literature recognizes the existence of gendered agricultural practices in many parts of the Global South (e.g. Arndt and Tarp, 2000; Doss, 2002; Ezumah and Di Domenico, 1995; Gladwin, 1992; Kevane, 2011; Sachs, 1996), practices that are generally enforced through both social norms and institutions such as land tenure (Agrawal, 2003; Tripp, 2004). For example, Carr (2011) demonstrates that the convergence of a male-controlled land tenure system and widely-held 
gendered roles and responsibilities in Ghana's Central Region lead women to select vegetable crops that are useful for subsistence consumption, as opposed to tree crops that are both more robust in the face of climate variability and more valuable in local markets.

Finally, a growing literature recognizes that the roles and responsibilities of individuals and groups with regard to agricultural production are shaped, not through a single identity, but through the convergence of multiple identities. In the context of gender, several authors have argued that focusing on the differences between men and women overlooks more complex identities within these broad categories that influence agrarian and climate change adaptation outcomes (Carr, 2008b; Dankelman, 2002; Demetriades and Esplen, 2008; Djoudi and Brockhaus, 2011; Kaijser and Kronsell, 2013; MacGregor, 2010; Warner and Kydd, 1997). A growing literature in both gender and development, and now gender and adaptation, recognizes that gender takes meaning in the context of age, caste, and livelihoods (see Carr and Thompson, 2014 for a review). Therefore, to gain insights into the causes of observed adoption patterns it is important to go beyond simple comparisons between women and men and consider which men and which women are adopting and why.

It is with this literature in mind that we seek to understand differences in adoption of drought-tolerant maize seeds by different farmers in the sample - not merely men and women, but also different kinds of men and women, where such differences reflect distinct roles and responsibilities that shape the patterns of observed agricultural decisions. This literature guides the development of an empirical model that enables us to test four hypotheses for how gender roles and responsibilities influence agricultural technology adoption. Before turning to the empirical modeling, however, the next section describes the Uganda household survey data and the study context. 


\section{Data and study context}

\subsection{Survey sites and data collection}

Data are from a household survey of 408 households and 696 individuals (householders and their spouses) in eastern Uganda, completed in 2014. The survey was a collaborative effort between the International Maize and Wheat Improvement Center (CIMMYT, lead institution), Michigan State University, Makerere University, and Uganda’s National Agricultural Research Organization (NARO). The geographical focus was eastern Uganda, where DTMA project activities have been concentrated. Three DTMA-dissemination districts were randomly selected to represent the region, and 34 villages were selected with probability proportional to size sampling, using information from the 2012 Uganda Census. From each sampled village, a simple random sample of 12 households was selected for interview.

The survey involved face-to-face interviews with household members using two structured questionnaires (a household and an individual questionnaire), a risk elicitation experiment with household members, and interviews with key informants using a village questionnaire. Household heads were the main respondents of the household questionnaire. In spousal-couple households, efforts were made to include spouses in the interviews. The household questionnaire collected information on demographics, agricultural landholdings, maize varieties cultivated, agricultural input use, quantity of maize harvested and sold, and socio-economic conditions.

For the individual questionnaire, the household head and, where applicable, the spouse was interviewed. The interviews with householders and their spouses took place concurrently but privately, and we usually matched the gender of interviewer to that of the respondent. The 
questionnaire collected gender-disaggregated data on drought-risk perceptions, technology preferences, awareness of and demand for DT maize seed, and access to information and credit.

The survey administered a risk elicitation experiment to sampled household heads and spouses to measure their risk preferences, using the Gneezy and Potters (1997) approach. After a detailed explanation of the 'game', respondents were privately asked to allocate among two fictitious maize varieties 0 to $10 \mathrm{~kg}$ of seed. One maize seed variety had the same yield and payoff regardless of rainfall conditions (good vs. bad); the other maize variety had a high yield/payoff when the weather was favorable, but a low yield/payoff under poor rainfall. The game had real payoffs (0 to 15,000 Ugandan Shillings), which depended on both the farmer's choice of maize seed allocation and the rainfall outcome determined by the roll of a die.

The village questionnaire was conducted with four key informants: a local council chairperson, a village extension officer, a progressive farmer; and a local opinion leader. This questionnaire was used to collect village-level information on demographics, economic activities, institutions and infrastructure, maize growing conditions, and wages/prices.

Several measures were taken to assure high quality data. To reduce respondent fatigue, households were visited in two rounds over the survey period. The household questionnaire was administered in June 2014; the individual questionnaire and risk experiment took place in July 2014. We set a maximum of four interviews per day per enumerator to reduce enumerator fatigue and allow time at the end of each day for field editing of the questionnaires. Enumerators were closely supervised throughout the survey by two supervisors and one of the authors of this paper. Where enumerators or supervisors found suspected errors or omissions, telephone calls or revisits with the respondent were required to correct or complete the questionnaire.

\subsection{Gender and access to, and control of, agricultural land in Uganda}


To assess the interrelationship between gender and agricultural production in rural Uganda, it is necessary to understand gendered roles, responsibilities, and access to agricultural resources, especially land and labor. In Uganda, the context of gendered roles and responsibilities varies between regions, but in general, strong patrilineal and patriarchal structures predominate so that women’s economic autonomy and access to, and control of, resources, particularly land, is relatively more constrained than elsewhere in East Africa (Kasente et al., 2002). The legal status of women has improved since the new constitution of 1995, but Ugandan women still face considerable de facto discrimination. For example, cultural practices related to land dictate that in much of Uganda women do not own land. Women gain access to land mainly through their relations with fathers, husbands, and brothers, and the land allocated to women by their male relations is often in the form of small fragmented plots on marginal lands. Women are often displaced from their land upon dissolution of their marriage or death of their spouse. Legal constraints to women's land ownership were eliminated with the new constitution, but women are often unaware of their rights (Kasente et al., 2002).

The CIMMYT Uganda survey collected information on gender-based differences in the ownership and control of agricultural land. For plots owned by the sampled households, respondents were asked which household member was considered the plot owner; up to two household members could be mentioned with the primary owner listed first. Respondents reported that $85 \%$ of maize plots were owned only by the household head, $2.5 \%$ by the spouse of the household head, and joint ownership applied to $12.5 \%$ of maize plots. Table 1a shows the primary owners of maize plots cultivated by relationship to the household head and gender of the individual. The data indicate that women farmers were the primary owners of $16 \%$ of maize plots, and men farmers for $84 \%$ of maize plots. 
[Insert Table 1a]

For cultivated maize plots, the Uganda survey asked respondents which household member had primary responsibility for decisions regarding the maize variety to cultivate. As with plot ownership, only household heads and spouses were mentioned as having such decisionmaking responsibility. The data indicate that women farmers were mentioned as the main decision-maker for maize variety for $26 \%$ of the plots (Table 1b). The considerable difference between married women’s ownership (2\% of maize plots, Table $1 \mathrm{a})$ and decision making (13\%, Table 1b) is likely explained by Uganda's patrilineal land inheritance system, as described earlier. Table $1 \mathrm{~b}$ shows that wives were the main decision-maker on maize variety for $13 \%$ of cultivated maize plots. Further data exploration reveals that only $5 \%$ of sampled wives had this decision-making role, often managing multiple maize plots.

[Insert Table 1b]

The Uganda survey data show some differences in maize plot characteristics based on gender and household status of the person who made decisions on maize variety for the plot (Table 2). Characteristics of plots managed by husbands in households headed by the wife are not included given there were only two such plots. Men household heads (MHHs) cultivated larger plots and had larger farm size than women household heads (WHHs). No statistically significant differences were detected among the three groups in terms of plot tenure and the farmer's assessment of their maize plots’ soil fertility and slope. Rain-fed maize farming was predominant for all categories.

[Insert Table 2]

\subsection{Gender and agricultural labor in Uganda}


Women and men have distinct roles in cropping systems throughout Uganda: they are engaged in the production of different crops and there is some gender division of labor in cropping activities. The degree to which the traditionally defined gender roles and responsibilities are followed in practice varies considerably across locations and over time (Kasente et al., 2002). Men tend to concentrate on cash crop production, especially when it is highly mechanized. Women, meanwhile, emphasize production of food crops, mainly for family consumption, while simultaneously providing much of the labor for cash crop production. In terms of specific agricultural tasks, one study found that women on average contributed $55 \%$ of labor for land preparation, $65 \%$ for planting, $85-90 \%$ for weeding, over 95\% for food processing, and a high percentage of rural water and fuelwood acquisition (Opio, 2003). In addition to supplying the bulk of agricultural labor, women are responsible for cooking, cleaning, and taking care of dependent household members (Kasente et al., 2002).

The CIMMYT Uganda survey did not collect data on family labor. Although labor is a crucial farming input, we opted for a survey instrument that prioritized collection of key data that can be collected with a reasonable degree of accuracy in rural Africa. Time allocation is notoriously difficult to collect in rural Africa where farmers rarely wear watches or keep track of hours allocated to various farming activities. We used the Uganda Living Standards Measurement Study (LSMS) for 2011/12 to explore patterns of labor availability on plots managed by WHHs, wives in spousal-couple households, and MHHs. Table 3 shows that farm plots managed by MHHs had greater overall numbers of household laborers than those plots where the main decision-maker was a WHH or a wife. Compared to men's plots, women's plots had access to greater supplies of women's and children's labor but lower access to men's labor. Note that the sum of the different categories of labor do not equal the total household labor 
supply because the Uganda LSMS survey instrument asked respondents for total number of laborers who worked a plot and then asked them to list the three household members most involved on the farm plot.

[Table 3 here]

\section{Modeling approach and research hypotheses}

\subsection{The empirical model}

The CIMMYT Uganda survey data are used to understand how gendered roles and responsibilities influence adoption of DT maize varieties. We estimate a multinomial logit (MNL) model in which the dependent variable is categorical, indicating the type of maize grown by a farm plot manager on her/his plot: local maize, non-DT modern maize, and DT modern maize. The selection of explanatory variables is based on review of three bodies of literature: the literature on gender roles and responsibilities reviewed earlier in the paper, as well as empirical research on agricultural adaptation (e.g., Jain et al., 2015; Below et al., 2012) and technology adoption in low-income settings (e.g., Doss, 2006; Feder et al., 1985). We categorize these explanatory variables as biophysical, economic, and social. Table 4 provides the definition, unit of analysis, and descriptive statistics for all model variables.

\section{[Insert Table 4]}

The empirical model includes biophysical factors to reflect maize growing conditions: land quality, proxied with a binary variable indicating the farmer rated her maize plot's soil quality as good; an indicator variable for irrigation on the plot; and altitude of the farmer's house. Biophysical factors, such as agroecology, are also captured by binaries for district of residence. Influential economic factors are the acreage and land tenure system of the maize plot, access to cash (proxied by the poverty score card) or credit to purchase seed and complementary 
inputs, awareness of DT maize seed, source of information, if any, on modern maize, and market access, measured by distance to the nearest agricultural inputs market. ${ }^{2}$ The poverty score card is a simple yet accurate and precise approach to measure poverty, based on ten indicators that measure household size, education of household members, housing conditions, and household goods’ ownership (Schreiner, 2011). Since labor supply and education are part of the poverty score, those variables are not included separately in the regressions.

As discussed above, the roles and responsibilities associated with particular sociodemographic categories also matter for farming decisions. To capture these factors, the model contains variables for the gender, relationship to the household head, and age of the farm plot decision-maker. We include variables that likely reflect gendered roles and responsibilities: the farm plot manager's willingness to take on agricultural risk, drought risk perception, and preference for specific maize variety traits. We measure willingness to take on risk based on the farmer's response to the risk elicitation experiment described earlier.

As measures of preference for maize variety attributes, we include binary variables for whether the farmer stated a preference for the two attributes on which the new DT maize varieties are promoted: yield and drought tolerance. A binary variable for whether the farmer mentioned a preference for consumption traits like taste, poundability, and flour-to-grain ratio is included. Finally, to control for seasonality, we include a dummy variable for the 2014 major rainy season.

\subsection{Research hypotheses}

${ }^{2}$ Prices for maize grain, maize seed, and fertilizer were collected at village level, but are not included among the economic factors, due to many missing values for these variables. 
The empirical model is used to investigate four main hypotheses for how gender influences adoption of new agricultural technologies. We begin by testing two hypotheses for gender gaps in modern maize adoption, related to differences between women and men farmers in (1) technology preference and (2) resource access. Two steps make up the testing of these two hypotheses. First, results of the MNL model indicate whether or not the hypothesized factors significantly influence cultivation of DT modern maize. Second, where significant association is found, we test for significant differences in the means of these variables across WHHs, married women, and MHHs.

The first study hypothesis concerns technology preferences. It has not previously been directly tested, but research suggests that in many contexts the specific roles and responsibilities of women and men farmers result in gender-based differences in preferences for crop species and varieties (Beuchelt and Badstue, 2013; Carr, 2008b). For example, research in Mexico and southern Africa (Bellon et al., 2006; for a review see Doss, 2001) found that men farmers often prefer high-yielding maize varieties and the opportunity to market surplus maize production, reflecting their role as the household's provider of cash income. Married women farmers in these contexts were found to prefer maize varieties that are palatable, nutritious, and meet processing and storage requirements given their responsibility for maize processing, storage, and cooking. Women who head households might be expected to have variety preferences that balance production and consumption traits, given their need to provide food for domestic consumption as well as generate income for other household needs. The different needs of different farmers are unlikely to be equally met by DT maize. Because crop breeders often do not consult women farmers, modern varieties generally do not match the specific criteria of women farmers for maturation periods, yields, taste, and other attributes (Quisumbing and Pandolfelli, 2010). 
To test the technology preference hypothesis, we include in the MNL model variables for farmer preference for yield, drought tolerance, and consumption traits in maize, and a droughtrisk perception variable. The rationale for the latter variable is that a farmer's appraisal of the threat of drought is associated with his or her motivation to adopt a new technology that can protect against moderate drought (Truelove et al., 2015). The second component of the hypothesis test rests on statistically significant differences in the technology preference variables for MHHs, WHHs, and wives in spousal-couple households.

In the literature, the observed lower agricultural-technology adoption rate among women vs. men farmers is most often attributed to women having reduced access to resources that enable adoption (Doss and Morris, 2001; Smale, 2011; Fisher and Kandiwa, 2014). For example, Doss and Morris (2001) studied 420 Ghanaian farmers and found that the observed lower-adoption rate among female farmers was not due to a lower propensity to adopt chemical fertilizer and modern maize seed, but reflected more limited access to complementary inputs, especially land, labor, and agricultural extension services. We complement previous tests of the resource access hypothesis with inclusion in the empirical model of several variables that reflect resource access: maize plot size and tenure, farmer assessment of the plot's soil quality, access to irrigation, the poverty score card, access to credit, and information access.

A third hypothesis follows the literature on gender and development discussed above, and moves the empirical analysis beyond simplistic associations between gender and technology adoption, which has been the dominant approach in the literature (e.g., Doss and Morris, 2001; Smale, 2011). To understand how the multiple identities of farmers and their associated roles and responsibilities impact technology adoption decisions as best as possible with the data at hand, the regression model disaggregates the sample into three groups: MHHs, WHHs, and wives in 
spousal-couple households. ${ }^{3}$ Poverty status and age are then interacted with the three farmer groups to generate 12 dummy variables. We take a simple approach to defining 'poor', 'nonpoor', 'younger', and 'older' farmers, using median values as cut-offs between groups. The inclusion of the dummy variables in the regression modeling allows us to identify the crop adoption-relevant identities of farmers within these groups, specifically how the influence of farmer gender on DT maize adoption differs, depending on whether a farmer is younger and poor vs. older and poor or younger and non-poor vs. older and non-poor. We refer to this hypothesis as the farmer identities hypothesis.

The fourth study hypothesis is that in spousal-couple households the adoption decision is reached through a bargaining process between the household head and the spouse. In line with this contention, we estimate an expanded regression model that adds explanatory variables reflecting the wife's labor availability and bargaining power for a sub-sample of plots where the decision-maker is a married MHH. While it would be insightful to run a separate regression for plots managed by wives and include the husband's characteristics as explanatory variables, the number of wife-managed maize plots is too few for viable results.

The ability to mobilize women's labor is expected to influence DT maize adoption where the counterfactual is cultivation of local maize. The switch from local to modern maize usually entails some increase in labor requirements, due to greater fertilizer application and the increased need for weeding when fertilizer is applied. Furthermore, the yield gain associated with switching from local to modern maize varieties should increase labor demand for harvesting and

\footnotetext{
${ }^{3}$ We initially disaggregated into six groups: married women heading households, unmarried women heading households, married men heading households, unmarried men heading households, wives in households headed by men, and husbands in households headed by women. Only the retained three groups had sufficient numbers $(n>30)$ to include in the regressions.
} 
processing activities. Since women do the bulk of crop weeding and processing in Uganda, adoption of DT maize is likely to increase demands on their time. It should not be assumed that women will willingly increase their workload when demand for their labor increases (Lilja, 1996; Jones, 1986). In the process of adopting new agricultural technologies, labor allocation within the household may be renegotiated, and to understand the adoption outcome it is important to be aware of what opportunities are available to women (and men), both on and off farm. Furthermore, studies reveal that women's bargaining power affects a range of outcomes, including adoption of new agricultural technologies (for a review, see Doss, 2013).

Women's bargaining power is often rooted in everyday actions of resistance, such as the withholding of domestic duties such as cooking (e.g. Carr, 2011), and therefore difficult to observe and a challenge to measure through surveys (Doss, 2013), but there are several useful proxies, including having resources such as income and assets (Agarwal, 1994; Quisumbing, 2003). Research suggests that the strength of a wife's bargaining power is better proxied by her relative traits in comparison with her husband rather than her absolute traits (GrossbardShechtman and Neuman, 1988). For example, being relatively well educated compared to her partner appears to have a stronger positive impact on a wife's bargaining power in the household than her absolute earnings (Koolwal, 2005). Similarly, it has been found that the age difference between partners is influential to individual bargaining power (Friedberg and Webb, 2006).

Building on the literature, we include in the expanded MNL model a binary variable for whether or not the wife had control over agricultural income or worked off farm, as a measure of the opportunity cost of her time spent working on her husband's maize plot. To measure the wife's bargaining power, in addition to the latter variable, we include three binary variables to indicate whether or not the wife was the sole owner or joint owner of a maize plot, had higher 
educational attainment than her husband, and was older than her husband. We include variables for the wife's age and education to assess if absolute or relative measures matter more.

\section{Results}

Table 5 presents goodness-of-fit statistics, marginal effects, and z-statistics for MNL models where the categorical dependent variable is cultivation of local maize, DT modern maize, and non-DT modern maize. We report results for DT maize cultivation only, but findings for local maize and non-DT modern maize are available upon request. The second and third columns of Table 5 report results for the full sample of maize plots and inform the technology preference and resource access hypotheses. The fourth and fifth columns introduce interaction terms to test the farmer identities hypothesis. The last two columns of the table are results for a sub-sample of spousal-couple households headed by a man. For the sub-sample MNL model, we include characteristics of the wife alongside those of the husband to gain insights on intra-household dynamics and their implications for agricultural technology adoption.

\section{[Insert Table 5]}

Starting with the goodness-of-fit measures at the bottom of Table 5, the pseudo$R^{2}$ statistics and the percent of correctly classified observations suggest our models fit the data reasonably well. To assess multicollinearity problems, variance inflation factors (VIFs) are computed for independent variables. The highest VIF is 2.80. Thus multicollinearity does not appear problematic. In Table 5, marginal effects are reported because coefficients can be difficult to interpret for the MNL model, given the need to compare to a base outcome. The $z$-values in the table are based on robust standard errors adjusted for clustering on village, to account for the random selection of villages and the natural clustering of households within them. 
Results in Table 5 indicate that, controlling for other important determinants, being a WHH or a wife decreases the average probability of growing DT maize by 26 and 16 percentage points, respectively $(p<0.05)$. Other factors found to be significantly and negatively associated with growing DT maize are having a preference for high-yielding maize and living at higher altitudes (the varieties are not suitable for cultivation above 1,600 meters). Adoption of DT maize is lower in Iganga and Tororo districts than in Bulambuli district. Variables having a positive association with DT maize adoption include market tenure of the maize plot, availability of credit, awareness of DT maize, receipt of information on modern maize seed from research centers, and the reported number of years in the last five in which drought resulted in maize harvest loss.

\subsection{Hypothesis 1: Technology preference}

To assess the evidence in favor or against the technology preference hypothesis, we first look at the marginal effects for the relevant variables in the second/third columns of Table 5. Two of these variables are found to influence DT maize adoption significantly: a preference for high-yielding maize and reported number of years in the last five in which the household experienced drought-induced maize harvest loss. That the proxy variable for perceived drought risk is positively associated with adoption of DT maize is as expected. The finding that preference for yield has a negative association with DT maize adoption may suggest that farmers mistakenly believe that cultivation of the new DT maize varieties entails a tradeoff between grain yield and drought risk mitigation. It may also signal a problematic interaction of DT varieties with those aspects of livelihoods currently aimed at managing agricultural risk, but the survey data at hand do not allow us to explore this possibility. We next examine the data for differences in technology preference between women and men farmers. 
The survey asked respondents to list their three preferred maize varieties and the three main characteristics that make the variety preferred. A total of 16 preferred varieties were mentioned, and women householders, wives, and men householders mentioned the same top three varieties. In terms of preferences for maize traits, a total of 29 maize traits were reported. The 10 most common traits were the same for women and men farmers, although there were slight differences in rank order across groups. No statistically significant differences are found between the three farmer groups in terms of preferences for grain yield or drought tolerance traits in maize. Among the top 10 ranked maize traits, consumption-related traits (fresh maize taste, posho taste, and posho quality) account for 27\%, 21\%, and 19\% of responses for WHHs, wives, and MHHs, respectively, with the differences between WHHs and the other groups significant. ${ }^{4}$

Next we ask if the data suggest differences between women and men farmers in drought risk perception, measured as the farmer's report on number of years in the last five in which the household experienced drought-induced maize harvest loss. The mean values for this variable are 1.80, 1.78, and 1.40 years for WHHs, wives, and MHHs, respectively, and none of the differences in means across groups is statistically significant $(p<0.05)$.

To summarize, the results suggest that technology preferences matter to a farmer’s decision to grow DT modern maize, but we find no evidence in support of the technology preference explanation for lower adoption of DT maize among women vs. men farmers. Demand for DT maize is found to be higher for farmers who perceived greater drought risk, but lower for farmers who expressed a preference for high-yielding maize varieties. No significant difference in drought-risk perception, yield preference, or drought tolerance preference is found between

${ }^{4}$ Posho is the word used in Uganda for a stiff porridge, usually made from maize, but also other starches. Elsewhere it is referred to as ugali (Kenya), sadza (Zimbabwe), and nsima (Malawi and Zambia). 
men and women farmers. WHHs are found to have a slightly higher preference for consumptionrelated maize traits, compared to MHHs and wives, but the MNL model results do not indicate an association between preference for consumption traits and DT maize adoption. The above findings together suggest no evidence in favor of the technology preference explanation for observed gender gaps, leading us to explore the resource access hypothesis in the next section.

\subsection{Hypothesis 2: Resource access}

Concerning hypothesis two, four resource access variables are statistically significant: market tenure of the plot, credit availability, awareness of DT maize varieties, and receipt of information on new seed from research organizations (columns 2 and 3 of Table 5). These findings are consistent with theory and previous empirical research (Place and Otsuka, 2001; Croppenstedt et al., 2003; Birkhaeuser et al., 1991).

As further hypothesis testing, we explore differences among women and men in the four influential resource access variables. The data show that $46 \%$ and $51 \%$ of WHHs' plots were under market tenure and customary tenure, respectively. Corresponding figures for wives are 48\% and 45\% and for MHHs are 41\% and 56\%. The numerical differences across farmer groups and are not significant. Access to credit is based on response to the survey question "If you need to borrow money to buy fertilizer, seed, and other inputs for maize production, how likely is it that you will be able to borrow money from your most likely source of credit?” Farmers who answered they were likely or extremely likely to access credit were considered as having good access to credit. The survey data reveal similar access to credit between WHHs (47\% reported good access) and MHHs (48\%). But wives in spousal-couple households are found significantly less likely to report good access to credit for agricultural input purchases (34\%). 
Turning to awareness and source of information on new seed, the survey asked farmers if they could name any DT maize varieties and found that 46\% (women householders), 59\% (wives), and 66\% (men householders) could name at least one, with significance to the differences in means only between WHHs vs. MHHs. Under the DTMA project and Uganda’s NARO, researchers typically expose farmers to new technologies through participatory varietal selection, agricultural shows, field days, and demonstration plots. The percentages of WHHs, wives, and MHHs that mentioned research centers as a main information source are $0 \%, 7 \%$, and 11\%, respectively, with the differences between MHHs and WHHs significant.

To summarize, empirical results provide some support for the resource access hypothesis. We find that married women farmers are less able to try new varieties partly due to lower access to credit than men farmers. Limited access to information on new seed appears an adoption constraint for WHHs who, compared to MHHs, are less aware of DT maize varieties and less likely to have benefited from agricultural research center activities (e.g. demonstration plots and field days). Given the high impact of research centers on DT maize adoption (Table 5), farmer uptake could greatly increase if more women and men farmers were reached by this source of agricultural information.

\subsection{Hypothesis 3}

The fourth and fifth columns of Table 5 display results for the 11 dummy variables that enable us to test the farmer identities hypothesis. The reference category for the dummy variables is a younger, non-poor MHH. One overall finding is that the marginal effects are small and insignificant for the different groups of men farmers, indicating that age and economic status are not influential to their DT maize adoption. Another general result is that women farmers have a lower probability of adopting DT maize compared to men farmers. However, the gender-age- 
poverty dummy variables reveal important differences between women farmers on the basis of age and poverty status. Among the non-poor women farmers, being older (i.e. above the median age of 42 years) is associated with reduced probability of adopting DT maize varieties. By contrast, among WHHs with poverty scores below the median, we find that being younger (vs. older) is associated with lower DT maize adoption.

The farmer group found to be least likely to adopt DT maize is young, poor WHHs. Interestingly, older, non-poor WHHs and wives are also highly unlikely to adopt DT maize. While the survey data at hand do not allow for a rigorous explanation of these patterns, they reveal that farmer identities have important impacts on agricultural technology adoption in the case of DT maize adoption in Uganda. These findings suggest that a qualitative research effort aimed at explaining the different rates of adoption of DT maize among these different groups of women, for example by exploring the different agricultural roles and responsibilities associated with each group, could yield important lessons for appropriate targeting of efforts to boost adoption among women and close adoption gaps between different groups in the population.

\subsection{Hypothesis 4}

The last two columns of Table 5 report results for a sub-sample of maize plots managed by a MHH of a spousal-couple household. The direction of association and statistical significance of explanatory variables is nearly the same as in the full sample models, which is not a surprise, because for most of the maize plots in the full sample the decision-maker is a married MHH. The only differences between the full-sample and the sub-sample MNL model concern the variables for receipt of information from public or private agricultural extension and a preference for maize consumption traits. 
The sub-sample model includes six additional variables that proxy a wife's opportunity cost of time or her bargaining power, and three of these are found significantly associated with DT maize adoption. Where women are the sole or joint owners of a maize plot their husbands are less likely to cultivate DT maize. Further if the wife is older or more educated than her husband he is less likely to grow DT maize. These three significant variables may be useful indicators of a wife's bargaining position following other studies (Doss, 2013; Friedberg and Webb, 2006; Grossbard-Shechtman and Neuman, 1988), and our findings may thereby indicate that an important factor limiting adoption of DT maize is the wife's attitude toward adoption.

Unfortunately, our study cannot reveal where this attitude originates. Is it that the wife is laborconstrained and unconvinced about the production and vulnerability benefits of DT maize? Alternatively, the wife may understand the benefits of DT maize but doubt they will reach household members other than the husband. As with hypothesis 3, qualitative research into the causes of these patterns could help establish the source of women's attitudes toward adoption, and the means by which these attitudes influence their husband's decisions and production.

\section{Discussion and conclusion}

This article, grounded in the literature on gender and development and gender and adaptation, uses new household survey data for Uganda to examine how gendered roles and responsibilities influence adoption of drought-tolerant (DT) maize, a new technology that can help smallholder farmers in SSA adapt to drought risk. A key study finding is that women and men farmers in Uganda do not have equal opportunities to adopt DT maize, mainly due to differences in resource access, notably land, agricultural information, and credit. Owing to Uganda's current practices of agricultural land ownership and control, women farmers make 
decisions on agricultural input use, such as what maize variety to grow, mainly when they are the head of their household. The CIMMYT Uganda survey data show that only $5 \%$ of sampled wives had decision-making power over one or more maize plots, and therefore the opportunity to independently adopt DT maize.

Where the sampled women farmers have agricultural decision-making power, their maize plots are far less likely to be planted in DT maize compared to plots managed by men farmers, with WHHs having a lower average adoption rate than wives. Empirical analysis reveals that limited awareness of the new DT maize varieties and low rates of participation in DT maize promotion activities (e.g., demonstration plots and field days) are primary barriers to adoption of DT maize among WHHs. Wives in spousal-couple households are about equally aware of DT maize varieties as MHHs, which may indicate that married men and women are informing each other about the new maize varieties. The study finds that the main factor related to the gender technology gap between wives and MHHs is that married women have relatively limited access to credit for purchasing maize inputs.

A second main finding of this paper is that the consideration of gender as a binary division between men and women does not adequately capture the dynamics that shape the patterns of DT maize adoption. Few studies of agricultural production and technology adoption have considered the differentiation of women and men by various characteristics and how such differentiation influences outcomes. Following the contemporary literature on gender and identity, which sees identity (and therefore an individual's roles and responsibilities with regard to agricultural practice) as the intersection of different social categories, we explore various intersections of gender with other identities, such as the relationship to the household head, age, and poverty status. While empirical results reveal that whether a $\mathrm{MHH}$ was younger or older, or 
poor or non-poor has no significant influence on DT maize adoption, important differences among different categories of women farmers are identified. The farmer group least likely to adopt DT maize is young, poor WHHs. Plausible explanations are that age is a proxy for farmer experience, and less experienced farmers may be slow to adopt new technologies, and poor farmers have less access to the capital required to purchase seed and fertilizer. Less easy to explain is the result that older, non-poor women farmers, both wives and WHHs, are highly unlikely to adopt DT maize. Follow-up qualitative work would help provide context to these quantitative findings, enabling us to better explain and interpret the results, particularly those findings that are counterintuitive.

A third important study finding is that wives can influence adoption of DT maize on plots controlled by their husbands. Men farmers married to women who own a maize plot are less likely to adopt DT maize. It is highly plausible that wives who own a maize plot prefer to devote time to their own rather than their husband's plot and are empowered to resist. Results show that men married to women who are older and more educated than themselves are less likely to adopt DT maize. Older, more educated women likely have higher status in their household and community and therefore greater ability to refuse the increased demands on their time associated with technology adoption. In addition, higher education should indicate a higher opportunity cost of time spent working on their husband's maize plot. As above, qualitative research methods could complement our quantitative findings by providing greater insight into how husbands and wives negotiate agricultural decisions in rural Uganda.

Overall, the results of the present study demonstrate that efforts to better understand agricultural technology adoption and enable the development of well-targeted and sociallyinclusive adaptation policies must move beyond simple binary classifications of gender to more 
intersectional, situational approaches that consider how gendered roles and responsibilities influence agricultural practices. Our results show that the reduction of gender gaps in DT maize adoption will require separate policies that are specifically aimed at different groups of women farmers: WHHs vs. wives in spousal-couple households, older vs. younger women, and poor vs. non-poor women. For example, adoption of DT maize by WHHs in Uganda is likely to increase when women farmers have good access to information on new seed. This might require adjustments to existing DTMA project promotional activities, such as ensuring the timing of field days are convenient for women, selecting women as contact farmers and managers of DT maize demonstration plots, and working with women extension officers wherever possible. To enable independent adoption of DT maize by married women who have control over maize plots, this group of women may need to be targeted for credit assistance or by making small, affordable packs of DT maize seed available in local markets. As for those wives who lack decision-making power over a maize plot, one concern is that their already long workdays may increase when their husbands adopt DT maize. Gender transformative approaches that challenge existing social norms may be relevant. For example, recent research has demonstrated the potential for participatory agricultural platforms (e.g., farmer field schools) to empower women and men to challenge unequal gender roles and transgress social boundaries (Humphries et al., 2012). Finally, the group of women farmers found least likely to adopt DT maize - young, poor WHHs - may require multiple forms of assistance to enable them to grow DT maize and adapt to drought risk, including access to information, credit, labor, and land. 


\section{References}

Agrawal, B., 2003. Gender and Land Rights Revisited: Exploring New Prospects via the State, Family and Market. J Agrar Change 3(1-2), 184-224.

Akeredolu, M., Asinobi, C.O., Ilesanmi, I., 2007. Gender and Trends in Production Constraints among the Bambara People of Mali. In Proceedings of the 23rd Annual Meeting of the Association for International Agricultural and Extension Education; Polson, Montana, pp. 1-13.

Arndt, C., Tarp, F., 2000. Agricultural Technology, Risk and Gender: A CGE Analysis of Mozambique. World Dev 28(7), 1307-1326.

Becker, L.C., 1990. The collapse of the family farm in West Africa? Evidence from Mali. The Geogr J 156(3), 313-322.

Bellon, M.R., Adato, M., Becerril, J., Mindek, D., 2006. Poor farmers’ perceived benefits from different types of maize germplasm: The case of creolization in lowland tropical Mexico. World Dev 34 (1), 113-129.

Below, T.B., Mutabazi, K.D., Kirschke, D., Franke, C., Sieber, S., Siebert, R., Tschernig, K., 2012. Can farmers' adaptation to climate change be explained by socioeconomic household-level variables? Global Environ Change 22, 223-235.

Beuchelt, T.D., Badstue, L., 2013. Gender, nutrition- and climate-smart food production: Opportunities and trade-offs. Food Sec 5, 709-721.

Birkhaeuser, D., Evenson, R.E., Feder, G., 1991. The economic impact of agricultural extension: A review. Econ Dev Cult Change 39(3), 607-650.

Blumberg, R. L., 1991. Income under female versus male control: Hypotheses from a theory of gender stratification and data from the third world. In Gender, family and economy, ed. R.L. Blumberg; Newbury Park, CA: Sage, pp. 97-127. 
Buechler, S., 2009. Gender, water, and climate change in Sonora, Mexico: implications for policies and programmes on agricultural income-generation. Gend Dev 17(1), 51-66.

Burke, M., Lobell, D., 2010. Food security and adaptation to climate change: What do we know? In Lobell D, Burke M (eds.) Climate Change and Food Security. Available at http://link.springer.com/book/10.1007\%2F978-90-481-2953-9.

Carr, E.R., 2008a. Between structure and agency: Livelihoods and adaptation in Ghana’s Central Region. Global Environ Change 18(4), 689-699.

Carr, E.R., 2008b. Men’s Crops and Women’s Crops: The Importance of Gender to the Understanding of Agricultural and Development Outcomes in Ghana’s Central Region. World Dev 36(5), 900-915.

Carr, E.R., 2011. Delivering Development: Globalization's Shoreline and the Road to a Sustainable Future. New York: Palgrave Macmillan.

Carr, E.R. (Ed.), 2014. Assessing Mali’s Direction National de la Meteorologie Agrometeorological Advisory Program: Preliminary Report on the Climate Science and Farmer Use. Washington, DC: United States Agency for International Development.

Carr, E.R., Thompson, M. C., 2014. Gender and Climate Change Adaptation in Agrarian Settings: Current Thinking, New Directions, and Research Frontiers. Geography Compass 8(3), 182-197.

CIMMYT, 2013. The Drought Tolerant Maize for Africa project. DTMA Brief, September. Available at http://dtma.cimmyt.org/index.php/about/background.

Croppenstedt, A., Demeke, M., Meschi, M.M., 2003. Technology adoption in the presence of constraints: The case of fertilizer demand in Ethiopia. Rev Dev Econ 7: 58-70 
Dankelman, I., 2002. Climate change: Learning from gender analysis and women’s experiences of organizing for sustainable development. Gend Dev 10(2), 21-29.

Demetriades, J., Esplen, E., 2008. The Gender Dimensions of Poverty and Climate Change Adaptation. IDS Bulletin 39(4), 24-31.

Deressa, T.T., Hassan, R.M., Ringler, C., Alemu, T., Yusuf, M., 2009. Determinants of farmers’ choice of adaptation methods to climate change in the Nile Basin of Ethiopia. Global Environ Change 19(2), 248-255.

Djoudi, H., Brockhaus, M., 2011. Is adaptation to climate change gender neutral? Lessons from communities dependent on livestock and forests in northern Mali. International Forestry Review 13(2), 123-135.

Doss, C., 2013. Intrahousehold bargaining and resource allocation in developing countries. World Bank Research Observer 28(1), 52-78.

Doss, C.R., 2006. Analyzing technology adoption using microstudies: Limitations, challenges, and opportunities for improvement. Agr Econ 34, 207-219.

Doss, C.R., 2002. Men’s Crops? Women's Crops? The Gender Patterns of Cropping in Ghana. World Dev 30(11), 1987-2000.

Doss, C.R., 2001. Designing agricultural technology for African women farmers: Lessons from 25 years of experience. World Dev 29 (12), 2075-2092.

Doss, C.R., Morris, M.L., 2001. How does gender affect the adoption of agricultural innovations? The case of improved maize technology in Ghana. Agr Econ 25, 27-39.

Ezumah, N.N., Di Domenico, C.M., 1995. Enhancing the role of women in crop production: A case study of Igbo women in Nigeria. World Dev 23(10), 1731-1744. 
Feder, G., Just, R.E., Zilberman, D., 1985. Adoption of agricultural innovations in developing countries: A survey. Econ Dev Cult Change 33, 255-297.

Fisher, M., Chaudhury, M., McCusker, B., 2010. Do forests help rural households adapt to climate variability? Evidence from Southern Malawi. World Dev 38(9) 1241-1250.

Fisher, M., Kandiwa, V., 2014. Can agricultural input subsidies reduce the gender gap in modern maize adoption? Evidence from Malawi. Food Policy 45, 101-111.

Friedberg, L., Webb, A., 2006. Determinants and consequences of bargaining power in households. Center for Retirement Research Working Paper 13; Boston College, Boston.

Gladwin, C.H., 1992. Gendered Impacts of Fertilizer Subsidy Removal Programs in Malawi and Cameroon. Agr Econ 7(2), 141-153.

Gneezy, U., Potters, J., 1997. An experiment on risk taking and evaluation periods. Q J Econ 112 (2), 631-645.

Grigsby, W.J., 2004. The Gendered Nature of Subsistence and its Effect on Customary Land Tenure. Soc Natur Resour 17, 207-222.

Grossbard-Shechtman, S.A., Neuman, S., 1988. Women’s labor supply and marital choice. J Polit Econ 96(6), 1294-1302.

Humphries, S., Classen, L., Jimenez, J., Sierra, F., Gallardo, O., Gomez, M., 2012. Opening cracks for the transgression of social boundaries: An evaluation of the gender impacts of farmer research teams in Honduras. World Dev 40(10), 2078-2095.

Jain, M., Naeem, S., Orlove, B., Modi, V., DeFries, R.S., 2015. Understanding the causes and consequences of differential decision-making in adaptation research: Adapting to a delayed monsoon onset in Gujarat, India. Global Environ Change 31, 98-109. 
Jones, C., 1986. Intra-household bargaining in response to the introduction of new crops: A case study from North Cameroon. In Understanding Africa’s rural households and farming systems, ed. Joyce Lewinger Moock. Boulder, CO: Westview Press, pp. 105-123.

Kaijser, A., Kronsell, A., 2013. Climate change through the lens of intersectionality. Environ Polit 0(0), 1-17.

Kasente, D., Lockwood, M., Vivian, J., Whitehead, A., 2002. Gender and the expansion of nontraditional agricultural exports in Uganda. Shifting Burdens, Gender and Agrarian Change under Neoliberalism, 35-65.

Kevane, M., 2011. Gendered production and consumption in rural Africa. Proceedings of the National Academy of Sciences 109(31), 12350-12355.

Kinsey, B., Burger, K., Gunning, J.W., 1998. Coping with drought in Zimbabwe: Survey evidence on responses of rural households to risk. World Dev 26(1):89-110.

Koolwal, G., 2005. Gender inequalities in development: The impact of networks and labor markets. Unpublished Ph.D. Dissertation, Cornell University, Ithaca, New York.

Koopman, J.E., 2009. Globalization, Gender, and Poverty in the Senegal River Valley. Fem Econ 15(3), 253-285.

Li, Y.P., Ye, W., Wang, M., Yan, X., 2009. Climate change and drought: a risk assessment of crop-yield impacts. Clim Res 39:31-46.

Lilja, N., 1996. Household decision making and women’s income in Mali. Unpublished Ph.D. Dissertation. Purdue University, West Lafayette, IN.

MacGregor, S., 2010. A stranger silence still: the need for feminist social research on climate change. Soc Rev 57(Supplement S2), 124-140. 
Molua, E.L., 2010. Farm income, gender differentials and climate risk in Cameroon: typology of male and female adaptation options across agroecologies. Sustain Sci 6(1), 21-35.

Opio, F., 2003. Gender mainstreaming in agriculture with special reference to Uganda: challenges and prospects. African Crop Science Conference Proceedings 6: 699-703.

Peterman, A., Behrman, J., Quisumbing, A., 2010. A review of empirical evidence on gender differences in nonland agricultural inputs, technology, and services in developing countries. IFPRI Discussion Paper 00975.

Place, F., Otsuka, K., 2001. Tenure, agricultural investment, and productivity in the customary tenure sector of Malawi. Econ Dev Cult Change 50(1), 77-100.

Quisumbing, A.R., 2003. Household decisions, gender, and development. A synthesis of recent research. International Food Policy Research Institute (IFPRI); Washington, DC.

Quisumbing, A.R., Pandolfelli, L., 2010. Promising approaches to address the needs of poor female farmers: Resources, constraints, and interventions. World Dev 38(4), 581-592.

Ragasa, C., 2012. Gender and institutional dimensions of agricultural technology adoption: A review of literature and synthesis of 35 case studies. Available at http://ageconsearch.umn.edu/bitstream/126747/2/IAAE.2012.gender.pdf.

Sachs, C.E., 1996. Gendered Fields: Rural Women, Agriculture and Environment. Rural Studies Series. Boulder: Westview Press.

Schreiner, M., 2011. A Simple Poverty Scorecard for Uganda. Available at http://www.microfinance.com/\#Uganda.

Simtowe, F.P., 2010. Livelihoods diversification and gender in Malawi. Afr J Agric Res 5(3), 204-216. 
Smale, M., 2011. Does household headship affect demand for hybrid maize seed in Kenya? An exploratory analysis based on 2010 survey data. Michigan State University Working Paper 115, East Lansing, MI.

Tripp, A., 2004. Women's movements, customary law, and land rights in Africa: The case of Uganda. Afr Stud Quarterly 7(4), 1-19.

Truelove, H.B., Carrico, A.R., Thabrew, L., 2015. A socio-psychological model for analyzing climate change adaptation: A case study of Sri Lankan paddy farmers. Global Environ Change 31, 85-97.

Warner, M.W., Kydd, J.G., 1997. Beyond Gender Roles? Conceptualizing the Social and Economic Lives of Rural Peoples in Sub-Saharan Africa. Dev Change 28(1993), 143168. 


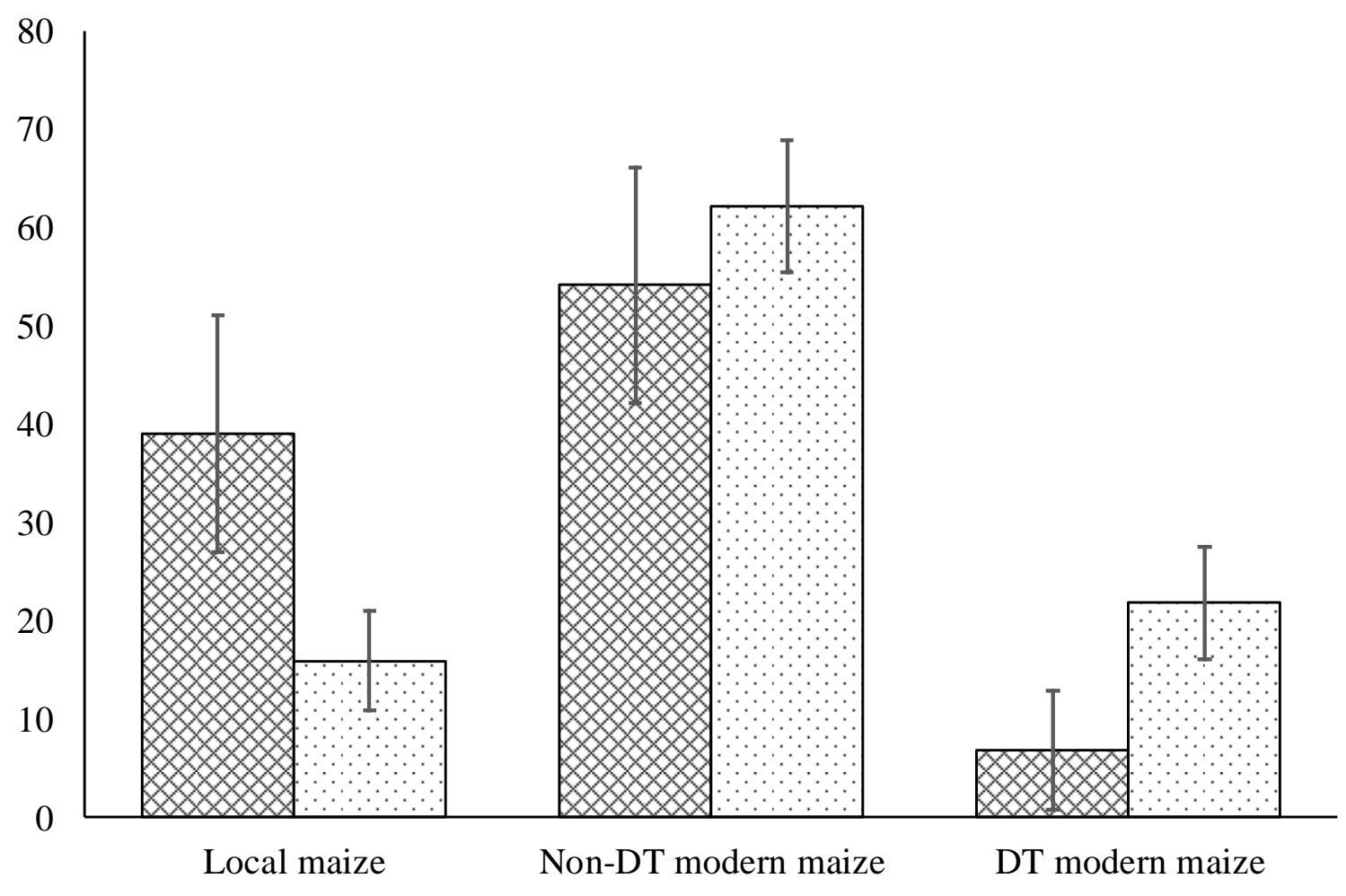

囚Women farmers' maize plots $\square$ Men farmers' maize plots

Figure 1. Percentages of maize plots cultivated in different types of maize and 95\% confidence intervals for the percentages, by gender of the maize plot decision-maker, CIMMYT Uganda Survey 2014 
Table 1a. Household status and gender of maize plot owners $(n=923)$, CIMMYT Uganda Survey 2014

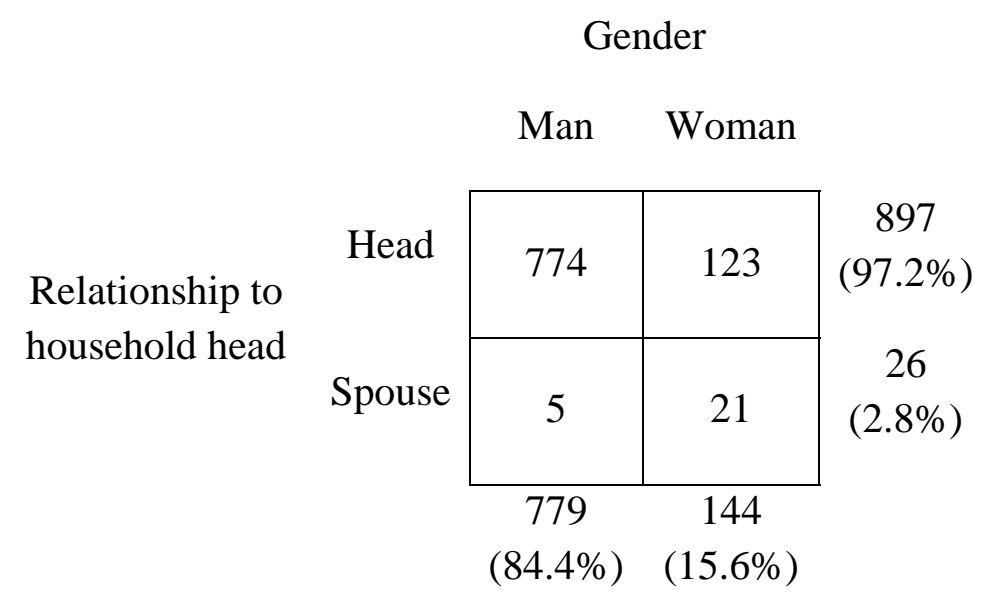

Table 1b. Household status and gender of maize plot decision-makers $(n=1,166)$, CIMMYT Uganda Survey 2014

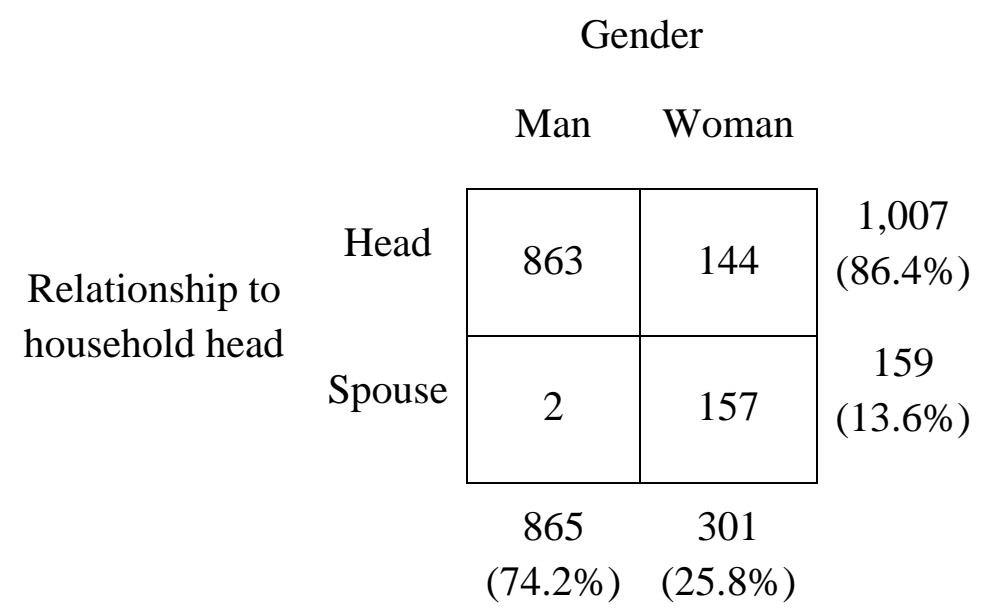




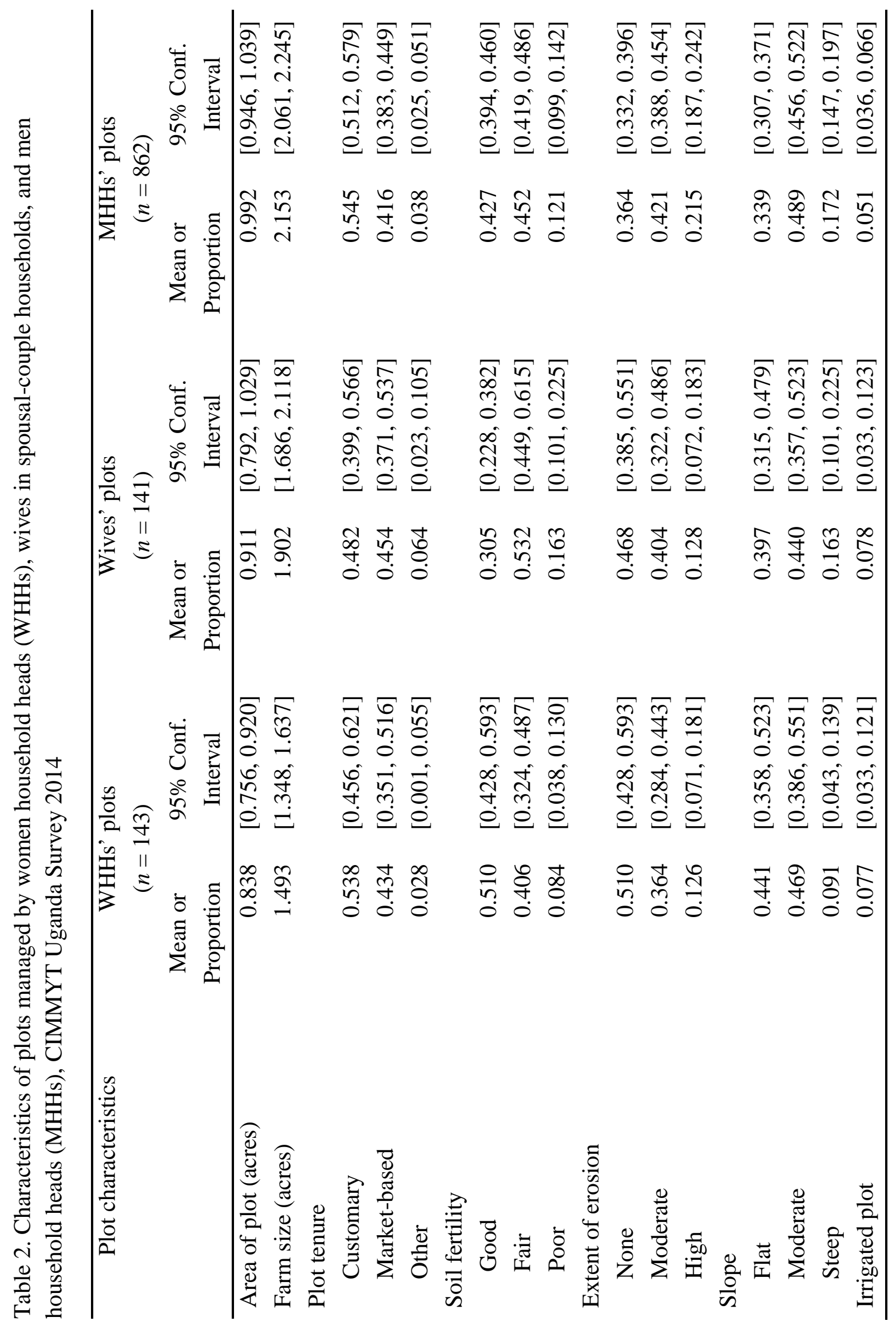




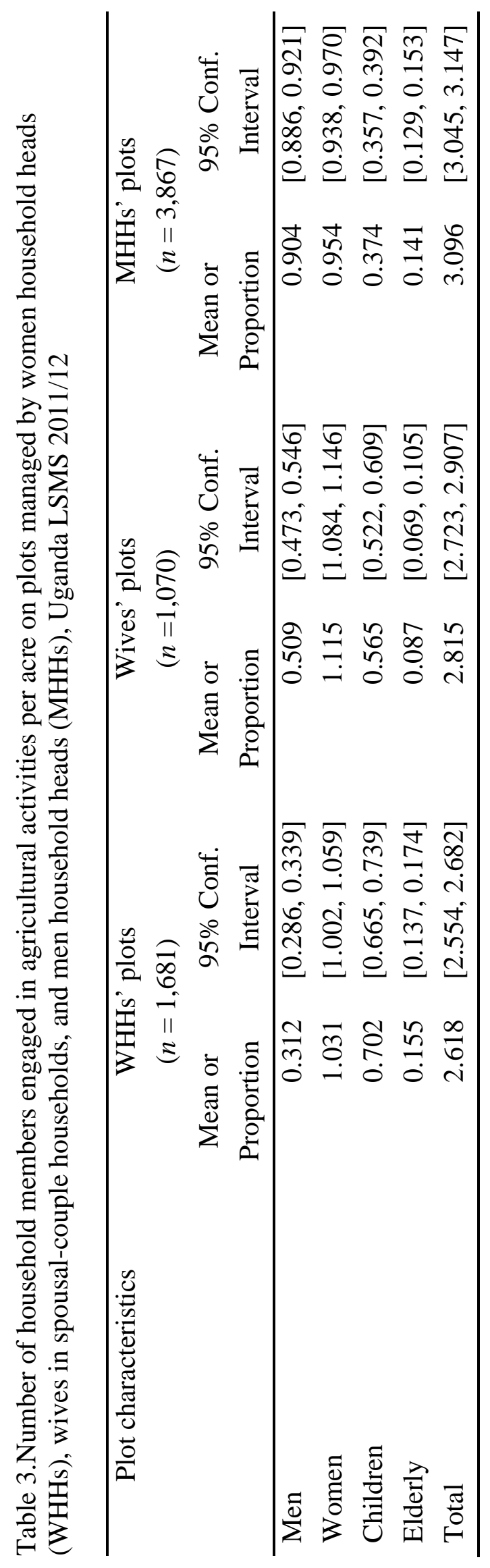




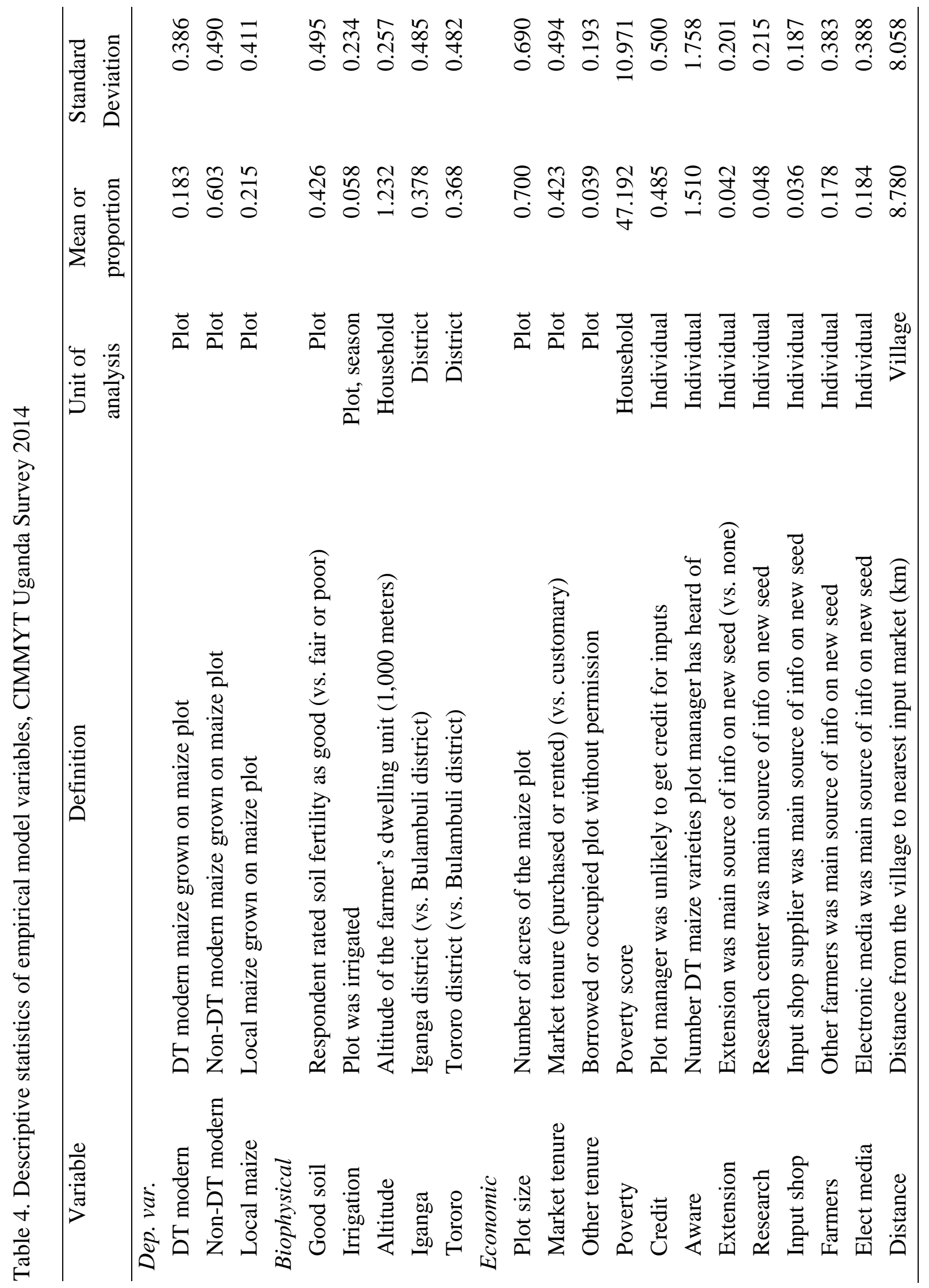




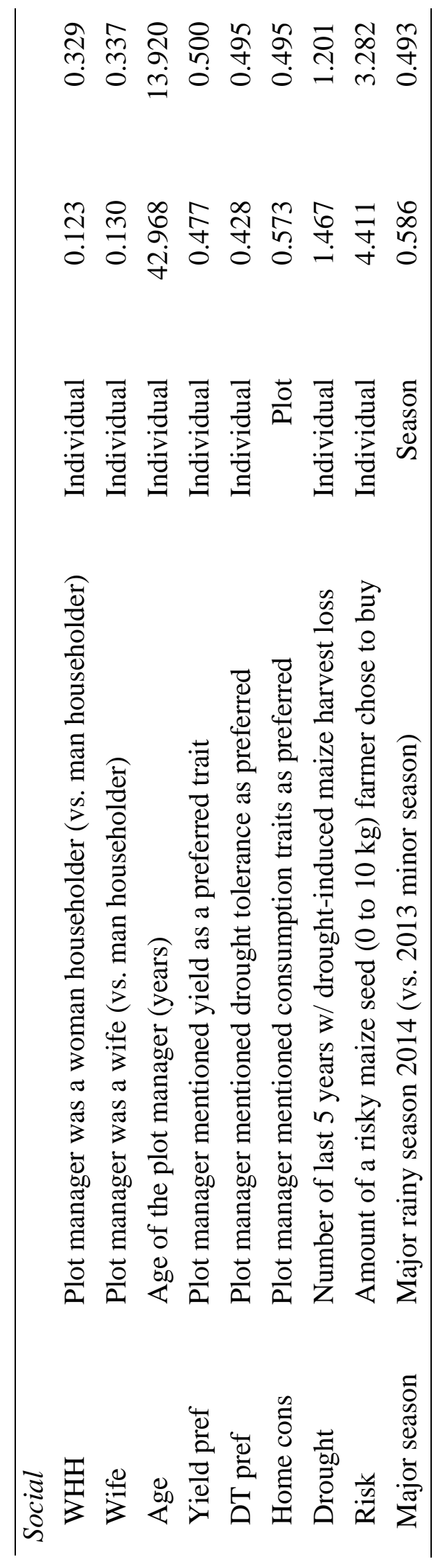




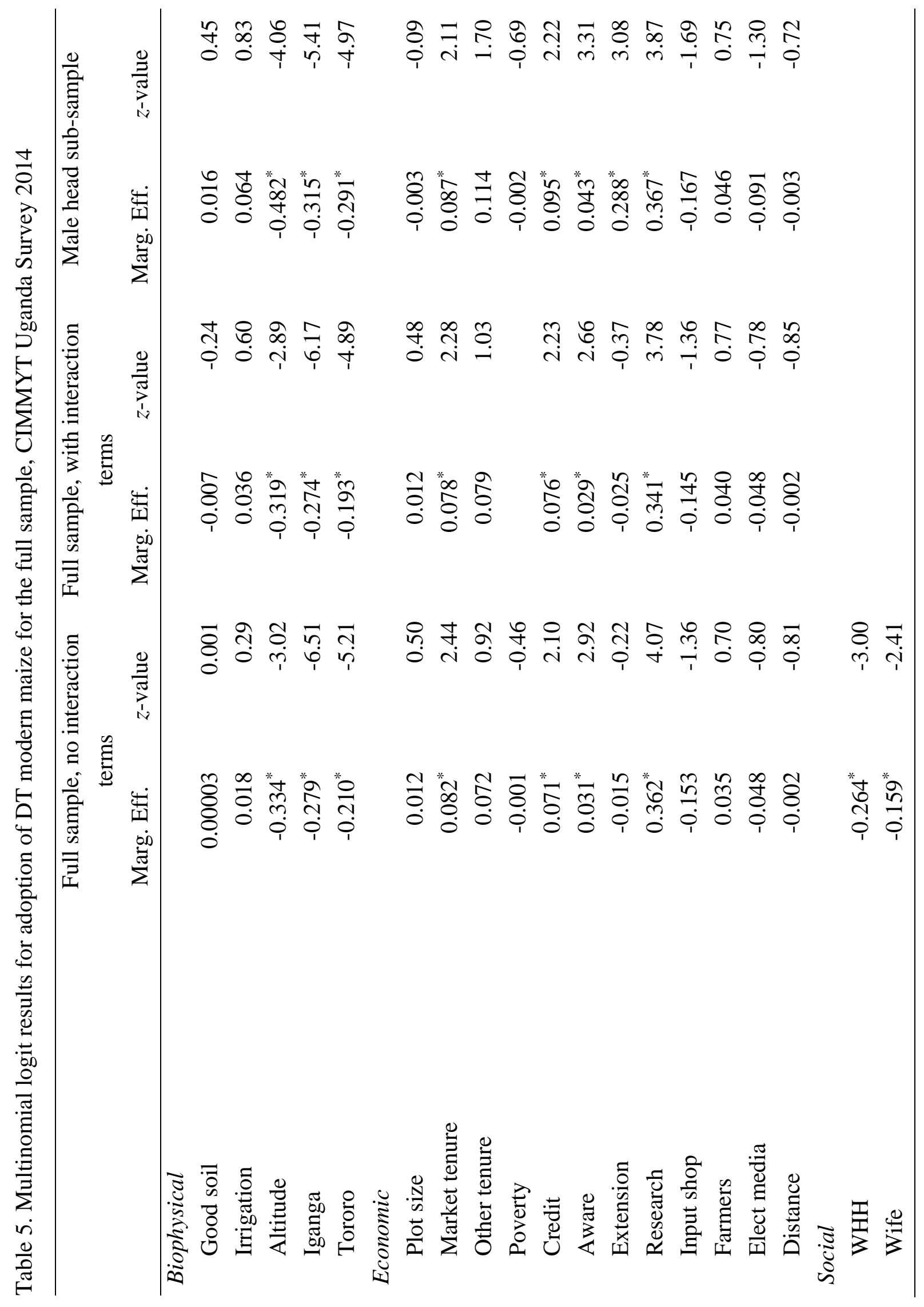




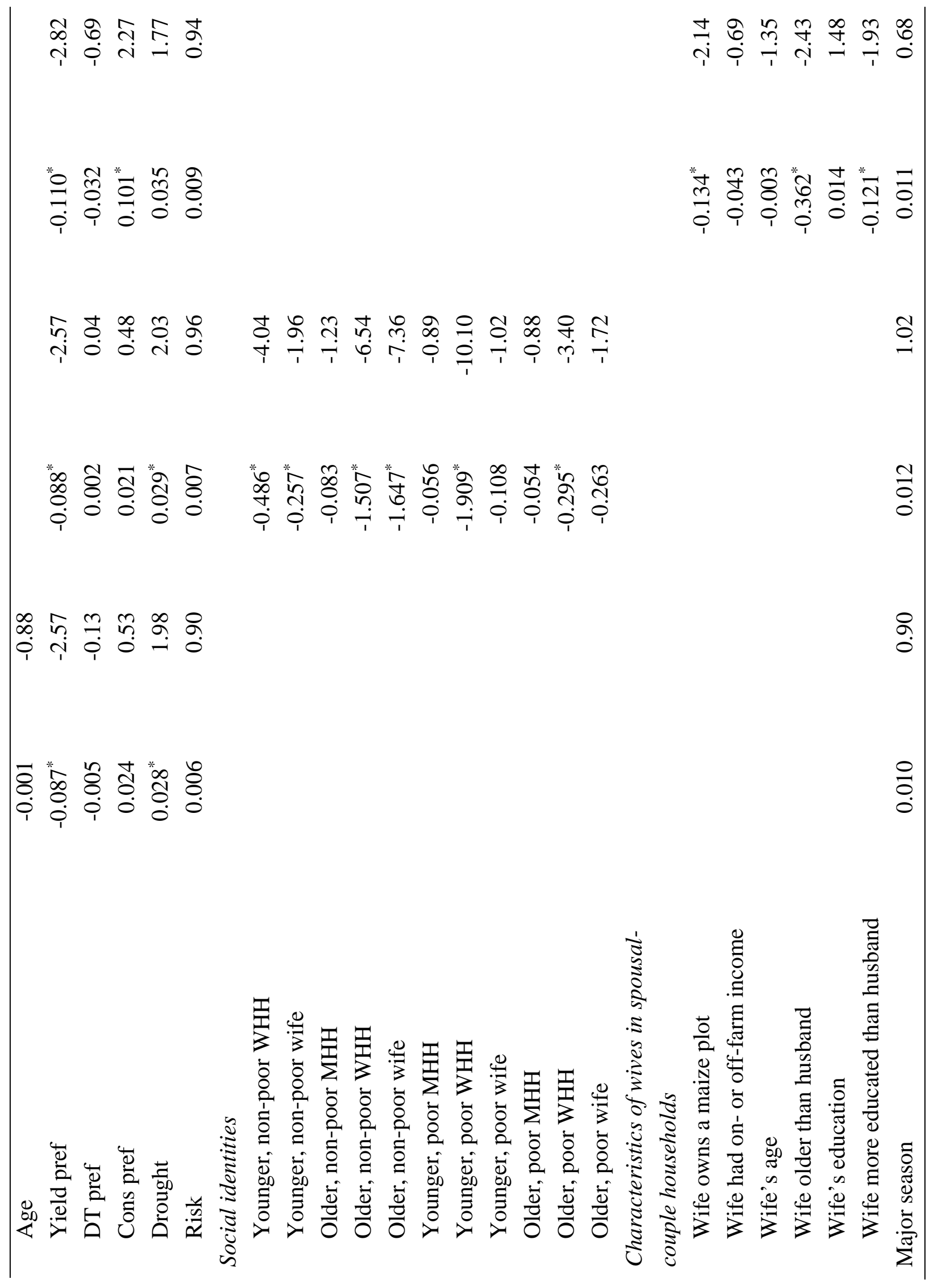




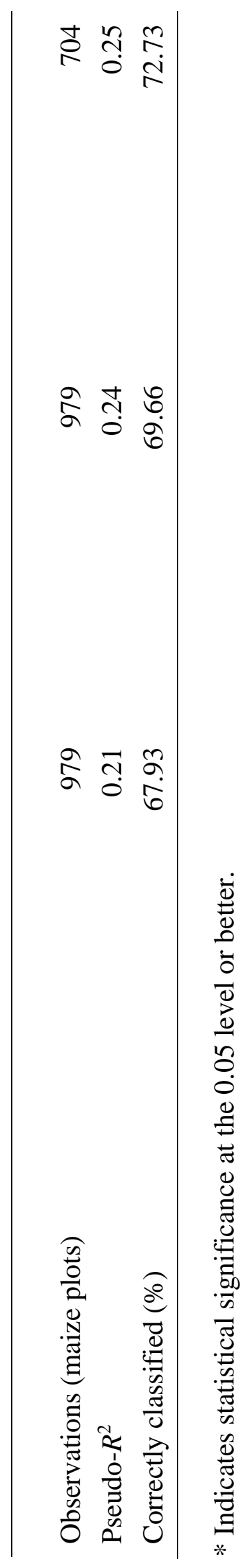

